\title{
„THE HISTORY OF THE TREE SPARROW IN JAPAN” BY FUMIO TAGUCHI, 2015, SELF PUBLISHED BY THE AUTHOR
}

The inspiration for writing this book and the concept of its content is best reflected in the email sent by Denis Summers-Smith, a Nestor and the worldwide authority in Sparrow research, to Fumio Taguchi, who was retired then, after the fulfilled career of a businessman, quoted by the Author in the Preface:

I think that it is time that you started compiling a book on "The History of the Tree Sparrow in Japan", not primarily about the biology of the bird, but the way the bird has influenced people in fables and folklore, in art ......, hunting and farming, sweetmeats, toys, up to present day gifts. Not that the biology should be ignored, but it should more concerned with people covering both the early „amateurs" up the current scientists and the current fields of research. In less than two years after this encouragement, a voluminous (633 pages), bilingual (with equivalent Japanese and English texts) book appeared, the content of which is realization of the concept proposed in the cited email. This is a well-documented monograph of the Tree Sparrow, written from the Japanese perspective. - describing its role for inhabitants of this country, its presence in the culture, and Japanese research on its biology.

After the Foreword written in a very personal way by J.D. Summers-Smith, and after the Preface written by the Author, the main part of the book is open the chapters Close relation between Man and Tree Sparrow in Japan and When the Tree Sparrow was recognized... It is not sure when the Tree Sparrow appeared in this country, but its cohabitation with people has been continued since the time of rice cultivation - about six thousand years, and for more than one thousand years it has been documented as a recognizable neighbor of man. Through centuries it has been known as a pest damaging crops in agriculture, but it also has reduced weeds and insect pests. It was hunted, nonetheless it has a preference for living near man.

The main content of the book is a review of the presence of the Tree Sparrow in Japanese culture. This subject covers the longest chapter with separately collected numerous notes and 26 tables with color illustrations. The theme of the Tree Sparrow is illustrated by many examples from different fields of art, artistic handicraft, belleslettres, fairy tales, folk beliefs, historical documents, or in music. Its picture was also applied in decorative art, clothes, postage stamps, coin, and its name was marked on sweets, in trade names, gastronomy, and trade.

The basic part of the book is closed by three shorter chapters. The first one concerns the occurrence of two other sparrow species in Japan - not abundant Cinnamon Sparrow Passer rutilans and the House Sparrow P. domesticus, recorded in Japan for the 
first time in 1990. The next chapter, Ecology of the Tree Sparrow in Japan, is not a direct characteristics of the ecology of this species, but rather a review of historical and recent research in Japan on the Tree Sparrow in this aspect. It also includes some personal reflections of the Author, e.g. on the origin of birds from dinosaurs. In general, this is a rather eclectic chapter, and not fully compatible with its title. In the last chapter of the book, Does Tree Sparrow in Japan have future?, in view of the House Sparrow crisis in London, the author wonders whether the fate of the Tree Sparrow in Tokyo may be similar. He hopes that this bird will be able to adapt to changing environmental conditions. This chapter, and at the same time the main part of the book, ends with Author's reflection ...if the Tree Sparrow or the House Sparrow becomes extinct, the next to disappear from the Earth can be ourselves.

By writing this book, Fumio Taguchi accomplished a unimaginably great and tedious work, in which his deep personal involvement is evident. He created a monograph documented in detail, which discovers for readers from outside the Japanese realm, the richness of a historical and cultural picture of the Tree Sparrow in his country, little known to us as yet.

Maciej Luniak

Museum \& Institute of Zoology PAS, Warszawa, Poland e-mailo: mluniak@pro.onet.pl 